\title{
The possibilities of the application of ion-plasma technologies to improve the wear resistance of the functional surfaces of power equipment elements
}

\author{
G. V. Kachalin, A. F. Mednikov, A. F. Mednikov \&
}

A. B. Tkhabisimov

Scientific Research Center "Wear Resistance",

National Research University "Moscow Power Engineering Institute”, Russian Federation

\begin{abstract}
The reliability and efficiency of power equipment is largely depend on the degree of wear in its most loaded elements, which during operation undergo the cumulative effects of various factors. The mutual manifestation of several kinds of wear leads to the intensification of the destruction processes that will reduce efficiency, and sometimes lead to the complete failure of power equipment. Nowadays, in the field of power engineering, different ways to improve wear resistance are used, but the problem remains unsolved. There is a necessity to develop new methods of universal protection based on modern technologies, which can effectively resist the combination of different kinds of wear. Modern ion-plasma technologies can be applied as the solution to this problem, which have broad application possibilities in surface layer modifications and the formation of multi-functional coatings. To solve such problems, the National Research University "Moscow Power Engineering Institute" (NRU "MPEI") created a unique experimental and industrial complex, which includes specialized ion-plasma equipment for coatings production, including large, cumbersome products (up to $3000 \mathrm{~mm}$ in length and up to $5000 \mathrm{~kg}$ in weight), experimental facilities for extensive materials and coatings testing, complex with the modern analytical equipment and appliances for studying the structure and properties of coatings. Laboratory results and field tests of ion-plasma coatings developed in NRU "MPEI" have shown that their use leads to a manifold increase in erosion,
\end{abstract}


abrasion, corrosion resistance, fatigue strength, heat resistance, and the significant reduction of the friction coefficient.

Keywords: power engineering equipment, droplet erosion, abrasive wear, corrosion, wear resistance, ion-plasma technologies, protective coatings.

\section{Introduction}

The current state of power engineering is characterized by the presence of a number of problems requiring immediate solutions in the near future. One of these problems - the progressive aging of the basic power equipment, causes the reduction of the reliability and efficiency of power plants.

Failures in the operation and premature failure of equipment components (turbines, steam generators, heat exchangers, stop and control valves, pumps, etc.) are largely due to their intense wear and ultimately depend on the efficiency and durability of the energy facilities. Despite the accumulated experience in dealing with various kinds of wear, the problem today remains unresolved.

Mutual influences of the various damaging factors lead to an intensification of the destruction processes of construction materials and an increases in the possibilities of equipment failure. In this regard, new methods and equipment protection technology must be developed universally, i.e. to effectively confront the combination of different kinds of wear.

In recent years, by developing methods and putting them into practice, fairly active efforts have been launched to improve the wear resistance of energy equipment elements due to the formation of protective coatings on the working surfaces. However, not all coatings and production technologies can be effective. Many coatings that have been successfully applied in other industries and turned out to be futile in the energy sector. In particular, this remark applies to the protective coatings used for the last stages of the working blades in powerful turbines.

The application of modern ion-plasma technologies, by strengthening materials and the formation of multifunctional coatings, can largely solve the problem or significantly slow the wear and improve the efficiency of power equipment operation.

\section{Current state of power equipment wear}

The analysis of the operation of power plants leads to the conclusion that almost all types of wear in power equipment are most evident in turbines. In the context of the turbines elements', the most significant types of wear are: droplet and abrasive erosion, cavitation, various types of corrosion, high temperature oxidation, etc. [1].

For high power steam turbines, the droplet erosion problem is extremely urgent, whereby the resource working blades of the last stages of turbines in some cases averages 50-55 thousand hours. Damage manifested as fatigue cracks on the input and output edges of the working blades, caused by the interaction of high-speed steam condensate drops with the working surfaces of the blades (see Fig. 1(a)) [2]. 
For energy equipment the problem of the abrasive erosion of the various elements remains essential. In particular this applies to the stop and control valve surfaces; the first stages of steam turbines. This kind of wear is so great that there is a need to repair them long before the assigned resource. Solid particles causing the wear of the steam turbine (see Fig. 1(b)), are products of corrosion and scale, which are taken out by the steam flow in the steam turbine [3]. The maximum size of the iron oxide particles is 300 microns and their hardness is 700-750 HV. According to American experts, the annual damage from abrasion in energy averages $1 \$$ per $1 \mathrm{~kW}$ of installed capacity, in some cases it increases by up to 3-3.5 times [3].

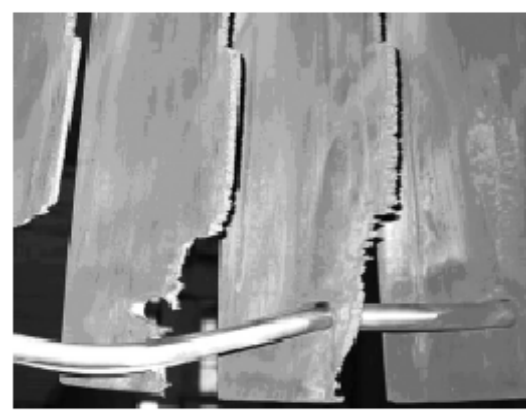

a)

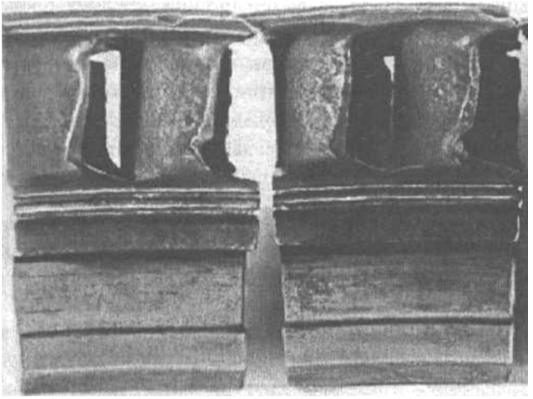

b)

Figure 1: The erosion (a) and an abrasive (b) wear of steam turbine blading.

Almost all heat-mechanical equipment during operation, so in periods after manufacturing transportation, storage, installation, repairs and downtime, is somehow affected by types of corrosion. Electrochemical corrosion is typical for energy, although, of course, chemical corrosion also takes place. The surfaces of the rotors, discs, blades and other elements of the turbines are exposed to these corrosive effects. The turbine blading and discs in the region of the phase transition experience significant corrosion and are exposed to damage.

The parts and components of gas turbines are also exposed to the combined effect of various damaging factors (high temperature oxidation, high mechanical and thermal stresses, etc.) that causes damage, wear the working surfaces and full or partial loss of efficiency, accompanied, in the end, by the reduction in the efficiency and significant economic losses (reduction and resource efficiency, increase the cost of repair).

Despite the fact that up-to-date technologies are used in different ways to improve wear resistance, the problem remains unresolved until the end. There is a need to develop new methods of universal protection with modern technologies, which can effectively resist the combination of different kinds of wear. Different perspectives and broad applications that modify surface layers are applied as a solution to this problem, including the formation of multi-functional nanocomposite coatings with modern ion-plasma technology. 


\section{Application perspectives of modern ion-plasma technologies}

Nowadays, there are a huge number of different methods for wear protection, but not all of them are useful and can withstand complex damaging factors. There are predetermined ways of dealing with certain kinds of energy equipment's structural material wear. Currently, a growing number of innovations in the global energy industry are on the way to opening up and creating new wear-resistant structural materials, different ways of hardenings, new multifunctional protective coatings with unique properties and characteristics. With their help, you can achieve a significant increase in the reliability and energy efficiency of heavy-duty pieces of equipment, and qualitatively create new properties of wear-resistant surfaces such as those of heat resistance and erosion resistance, with high microhardness, a low coefficient of friction, etc.

It should be noted that there are special requirements for developing ways to protect the most critical elements of the equipment, such as:

- resistance to mechanical, chemical and impact wear;

- sustained continuity and high adhesion properties under the influence of operating loads;

- no negative influence of surface modification parameters on the structural materials mechanical properties;

- high corrosion resistance;

- satisfy conflicting demands of surface (high wear resistance, hardness and adhesion, low friction) and volume (high strength and toughness) properties can be achieved by the creation of new materials and coatings with composite structure.

The most effective in this direction is ion-plasma technology. The prospects of its wide application are based on a number of the following characteristic features of processes [4]:

- high energy of particles $\left(10-10^{3} \mathrm{eV}\right)$, which provide totally different physical conditions of the deposited substances interaction with the protected surface;

- almost unlimited choice of metals and alloys for the formation of coatings, and synthesis of whole new class of materials with unique properties (nitrides, carbides, carbonitrides, etc.) based on them;

- a combination of coating's ultra-high hardness with high viscosity and low value of internal stresses;

- possibility of forming a multilayer, multicomponent and nanocomposite coatings providing high erosion and corrosion resistance in combination with high ductility and low friction coefficient;

- ecological safety of processes and high performance of materials' refinement.

\section{Experimental-industrial complex NRU "MPEI"}

To solve the problems of increasing the wear resistance of power equipment elements, the National Research University "Moscow Power Engineering 
Institute" (NRU "MEI") established an experimental-industrial complex, which includes:

- specialized ion-plasma equipment for coating's obtainment;

- test benches and rigs for extensive testing of materials and coatings;

- a complex of modern analytical equipment and devices for studying the structure and properties of coatings.

Technological research into the formation, including coatings with structure of the nanocomposites (Fig. 2 (a)), was conducted using several types of original ionplasma equipment, especially designed for the treatment of lengthy products (rotor blades, shafts, etc.). For the formation of coatings on large-sized products (length $3000 \mathrm{~mm}$, weight up to $5000 \mathrm{~kg}$ ) an unparalleled vacuum unit "Hephaestus-18$4 \mathrm{~m}$ " was applied (see Fig. 2, [5]).

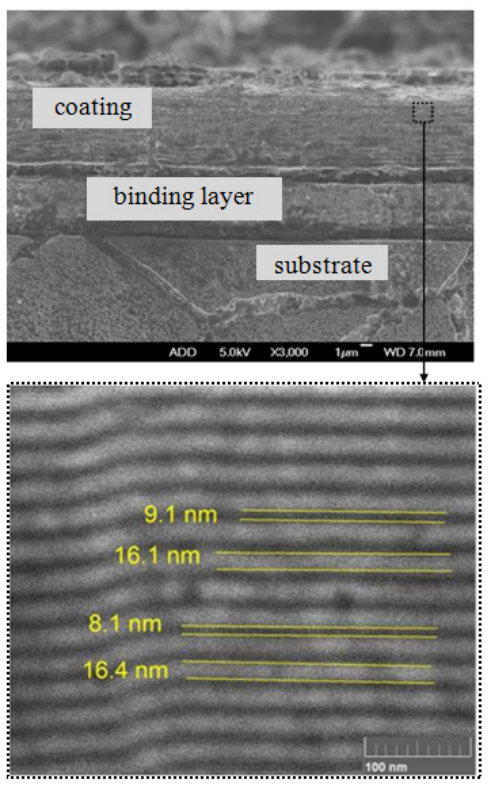

a)

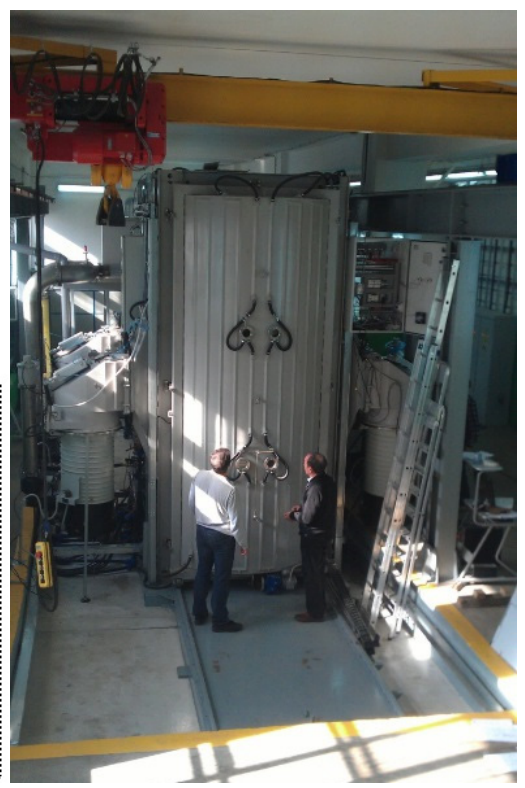

b)

Figure 2: $\quad$ Photo of ion-plasma 2D nanocomposite coating transverse section (a) (NRU "MPEI" development) and a general view of the vacuum unit "Hephaestus-18-4M" (b).

A complex of analytical research and test equipment allows us to determine and control the physical and chemical properties of materials and coatings and carry out certification tests with the definitions:

- macro-, micro-and nanohardness;

- parameters of roughness and size of the individual characteristic features of the surface relief;

- microstructure and chemical composition of the material or coating;

- variations of the friction coefficient depends on the path length, travel time 
and number of cycles;

- adhesion properties by sclerometry method;

- corrosion and abrasive resistance;

- fatigue characteristics, including characteristics in terms of working environment's increased aggression and typical for dynamic loads operating conditions;

- heat resistance.

Investigation into the fracture processes in a wide range of simulated conditions for the shock interaction of the test material and liquid, definition of the structural materials erosion resistance, and various types of reinforcements and protective coatings (see Fig. 3 (a)) was conducted, including the use of high-speed camera and video. This research was carried out using a unique experimental erosion stand "Erosion-M" NRU "MPEI" (see Fig. 3 (b)).

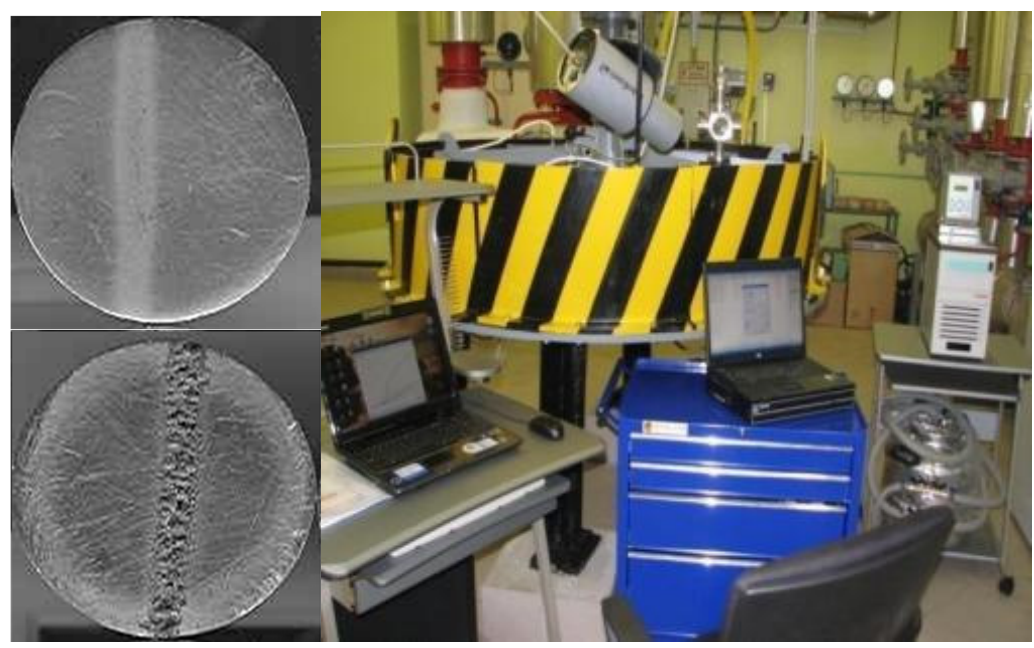

a)

b)

Figure 3: Samples of blade steel with NRU "MPEI" nanocomposite coating (a) (top) and uncoated (bottom) after erosion test and the experimental rig for erosive researches (b).

\section{Testing results of wear-resistant ion-plasma coatings}

The laboratory results and field tests of the ion-plasma coatings developed in NRU "MPEI" have shown that their use leads to a manifold increase in erosion, abrasion, corrosion resistance, fatigue strength, heat resistance, and significant reduction of friction coefficient.

Up to date, using the experimental and industrial complex, NRU "MPEI" tested different ways to improve the erosion resistance of blade materials and designed multilayer coatings $(10-20 \mathrm{~m} \mu)$, which offer enhanced erosion resistance of up to 5-6 times (see Figure 4). 


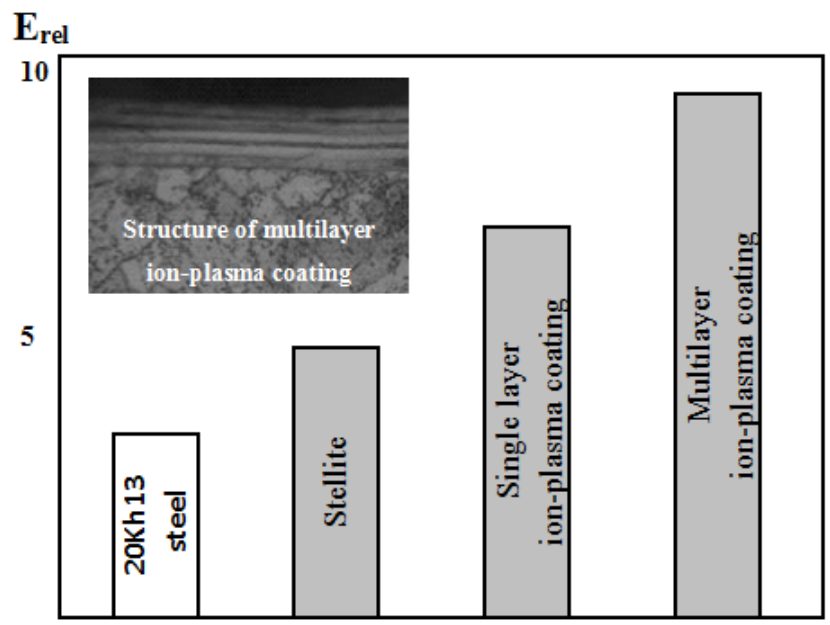

Figure 4: Relative erosion resistance of ion-plasma coatings formation on the blade steel $20 \mathrm{Kh} 13$.

In Fig. 5, in the form of dependency of the friction coefficient of the mean free path, the results of the "ball-disc" tribological tests on a titanium alloy with coating obtained at $236 \mathrm{MPa}$ contact stress and the characteristic of real operating conditions of high pressure valves are presented. An analysis of these dependencies shows that using multiple coatings helps to reduce the coefficient of friction of the titanium alloy.

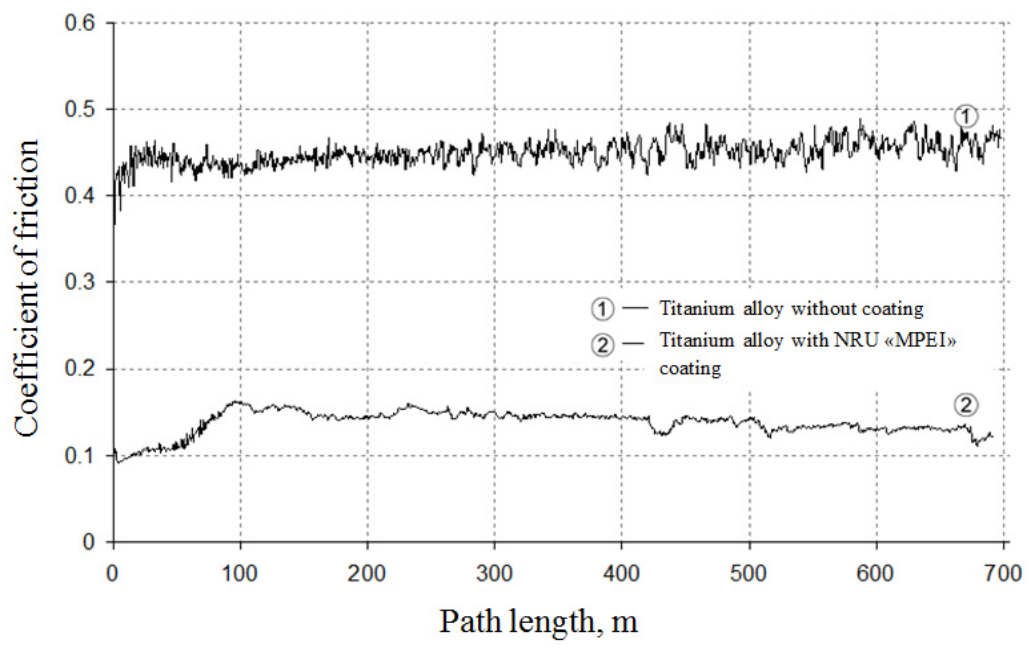

Figure 5: The coefficient of friction of the titanium alloy before and after coating formation. 
Today, with the use of an experimental and industrial complex, NRU "MPEI" developed and implemented nanocomposite coatings to increase wear of most loaded elements of various equipment, in particular for strengthening the working blades of the powerful steam turbines last stages (see Fig. 6(a)). An integrated technology of ion-plasma treatment of chromium steels instead of galvanic chromium coatings was developed and implemented, as well as the technology of coating thickness of up to $100 \mathrm{~m} \mu$ to reestablish the control valves. The equipment of the experimental and industrial complex is used for hardening serial batches of stop valves (see Fig. 6(b)) for gas-condensate fields with a high content of hydrogen sulfide. For new types of high-temperature steam turbines, a significant amount of work on the design and development of technologies forming 2D nanocomposite coatings was carried out (increasing the heat resistance of the blade materials by up to $5-6$ times) [6].

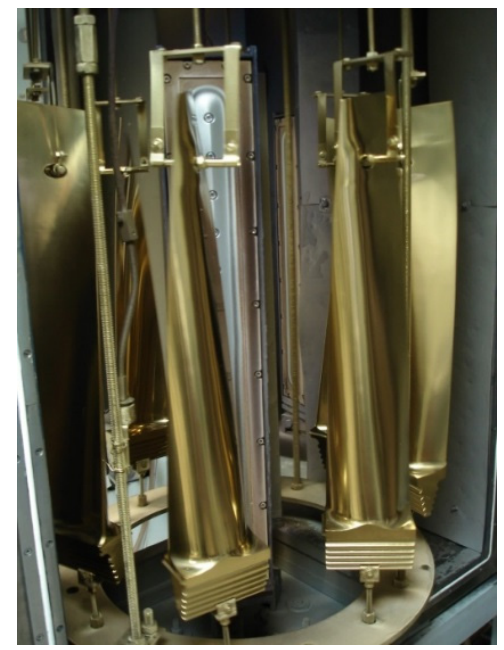

a)

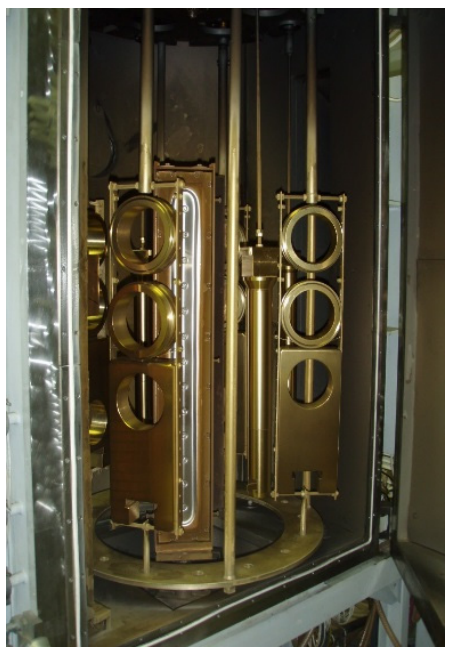

b)

Figure 6: Working blades of the powerful steam turbine last stages (a) and elements of stop valves (b) in a vacuum chamber after the installation process cycle.

The technologies developed and the protective coatings are used for:

- elements of stop, control and slide valves for gas-condensate fields;

- working blades of steam turbines last stages (blades over a length of $1000 \mathrm{~mm}$ );

- elements of energy complex and aviation equipment operated at high temperatures;

- large parts of the energy equipment. 


\section{Acknowledgement}

This work was supported by the financial support of the Ministry of Education and Science of the Russian Federation, Grant Agreement No. 14.574.21.0011 from June 17, 2014.

\section{References}

[1] Ryzhenkov V.A., Kachalin G.V., Pogorelov S.I., Starikova O.V. \& Ter-Arutyunov B.G. Prospects of ion-plasma coatings application for improving the wear resistance of power equipment elements. New in the Russian electric power engineering Energy-press: Moscow, 3, pp. 16-25, 2004.

[2] Dolzhanskiy P.R. \& Dobrokhotov S.E. Improved operational reliability of working blades of the last stages of turbines T-250/300-240. Reliability and safety of power engineering, 1, 2008.

[3] Trukhniy, A.D. \& Lomakin B.V. Cogeneration steam turbines and turbine installations, MPEI, Moscow, 2002.

[4] Ryzhenkov V.A., Fedorov V.A., Kachalin G.V. \& Mednikov A.F. Increasing the corrosion resistance of high-temperature turbine blades. Reliability and safety of power engineering, 2(5), pp. 34-39, 2009.

[5] Kachalin G.V., Ryzhenkov V.A. \& Mednikov A.F. Innovative technology complex for forming ion-plasma multifunctional coatings on large slide valves surfaces, Natural and technical sciences, 2, pp. 168-174, 2013.

[6] Kachalin G.V., Ryzhenkov V.A., Ter-Arutyunov B.G. \& Mednikov A.F. Hardening of stop and control valve's elements using ion-plasma technologies. Technology of metals, 4, pp. 19-21, 2007. 